\title{
Epithelial-Myoepithelial Carcinoma of High Grade Transformation: The Case Report in the Buccal Mucosa
}

\author{
Francisco Jadson Lima ${ }^{1, *}$, Damião Edgleys Porto $^{2}$, Josuel Raimundo Cavalcante ${ }^{1}$, Salomão Cury- \\ $\mathrm{Rad} \mathrm{Oka}^{1}$ and Gustavo Pina Godoy ${ }^{1}$
}

\author{
${ }^{I}$ Dentistry Postgraduate Program, State University of Paraíba, Brazil \\ ${ }^{2}$ Oral and Maxillofacial Surgeon, Pivate Practice, Brazil
}

\begin{abstract}
Epithelial-myoepithelial carcinoma was first described by Danath et al. in 1972 and is classified as a rare low-grade biphasic neoplasm of the salivary glands. This case report presents a male patient who had a lesion in the oral mucosa with a history of recurrence of the tumor. The outcome resulted in a profile consistent with an epithelial-myoepithelial carcinoma with a high degree of transformation. The case highlights the importance of histopathological evaluation of oral lesions, which occasionally may not present typical clinical aspects of malignant lesion.
\end{abstract}

Keywords: Dentistry, Diagnosis, Oral Cancer, Oral Diagnosis, Pathology, Salivary Glands.

\section{INTRODUCTION}

Epithelial-myoepithelial carcinoma (EMC) was first described by Danath et al. in 1972 and classified by the World Health Organization (WHO) in 1991 as a rare low grade of malignancy tumor, representing about $1 \%$ to $2 \%$ of all primary tumors of salivary glands $[1,2]$.

The average age of patients diagnosed is 60 years and approximately $55 \%$ of them are women ${ }^{1}$. In $80 \%$ of cases EMC affects the parotid gland. The second most frequent site is the submandibular gland, in $10 \%$ of the cases [1-3].

The histology of this neoplasm is unique over the others, since it is characterized by presenting two distinct cell populations: one composed by myoepithelial cells, that are apparently larger, with clear cytoplasm, and arranged around the other cell population, which features in a centrally and generally in an inferior arrangement [4].

Light microscopy and staining with hematoxylin-eosin, in general, are the basis for the diagnosis of EMC [4]. Treatment is varied and the surgical incision with a safety margin is strongly recommended. Subsequent radiation and chemotherapy may be necessary $[2,4]$.

This report brings a rare presentation of EMC in the oral mucosa with high-grade transformation.

\section{CASE REPORT}

A male patient, aging 61 years, presented himself to a public reference dental clinic and reported a "lump in the

*Address correspondence to this author at the Dentistry Postgraduate Program, State University of Paraíba, Brazil Rua Juvêncio Arruda, S/N Bodocongó Departamento de Odontologia - Campus Bodocongó CEP: 58.429-600; Tel: 55 (83) 3315-3471; Fax: 55 (83) 9626 - 7573;

Emails: odonto2006.1jadson@gmail.com, fjadsonl@yahoo.com.br cheek bothering for 8 years". This lesion had been previously removed, but presented local recurrence. The patient's medical history showed no major pathologies on his systems and he denied drinking, smoking or cancer in the family.

On intra oral examination, the left buccal mucosa showed a lesion with tumor aspect. It had the same color of normal mucosa, was hard, showed slow growth and exophytic and sessile deployment. It also had a smooth surface and a welldefined boundary (Fig. 1).

Therefore, imaging examinations were requested. The coronal CT scan with soft tissue and hard tissue window revealed a nodular area with soft tissue density, limits partially clear, measuring $2 \times 2 \times 1 \mathrm{~cm}$ (Fig. 2). We conducted an incisional biopsy and histopathological examination stained with hematoxylin-eosin which revealed dense proliferation of oval or elongated cells, consistent with a picture of unspecified neoplasm of salivary gland. We also conducted an immunohistochemical examination to clarify the histogenetic origin of the lesion.

So, under local anesthesia and through an elliptical incision, with a safety margin of $1 \mathrm{~cm}$ we did the removal of the lesion. Then this new specimen was sent for histopathological and immunohistochemistry analysis to confirm the histogenetic origin of the lesion (Fig. 3).

The histology revealed ductal formations showing an inner layer of cuboidal cells. It also revealed proliferation of polygonal cells arranged in a solid way (Fig. 4).

The immunohistochemical evaluation was positive for antibodies AE1/AE3, S-100, p63 and Ki-67 in about 25\% of neoplastic cells, resulting in a profile consistent with an epithelial-myoepithelial carcinoma with high-grade transformation (Fig. 5, 6, 7 and 8). The patient was referred to an oncology service to follow up the case. 


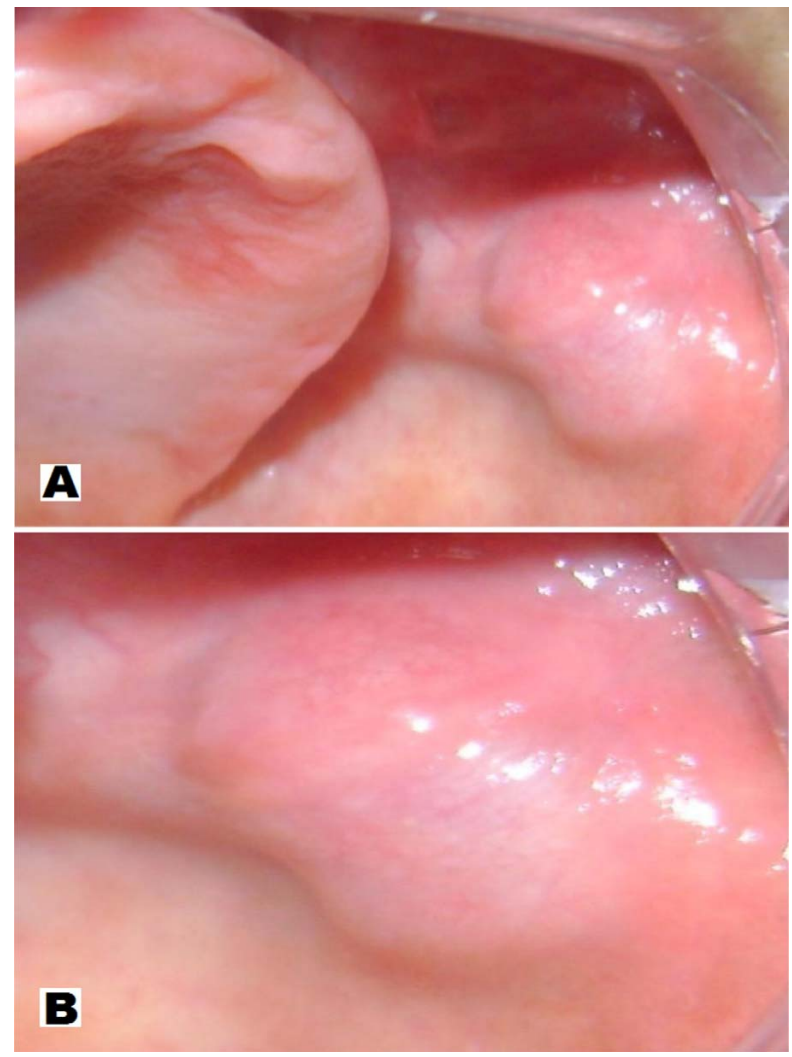

Fig. (1). Clinical Overview: A - (smaller increase) tumor appearance, color of mucosa, slow and exophytic growing, sessile deployment, smooth and well delineated surface. B - major increase.


Fig. (2). Axial CT scan showing a nodular image with sharp boundaries in part, measuring approximately $2.0 x 1.0 \mathrm{~cm}$. A $-\mathrm{CT}$ soft tissue window. B - CT hard tissue window. 

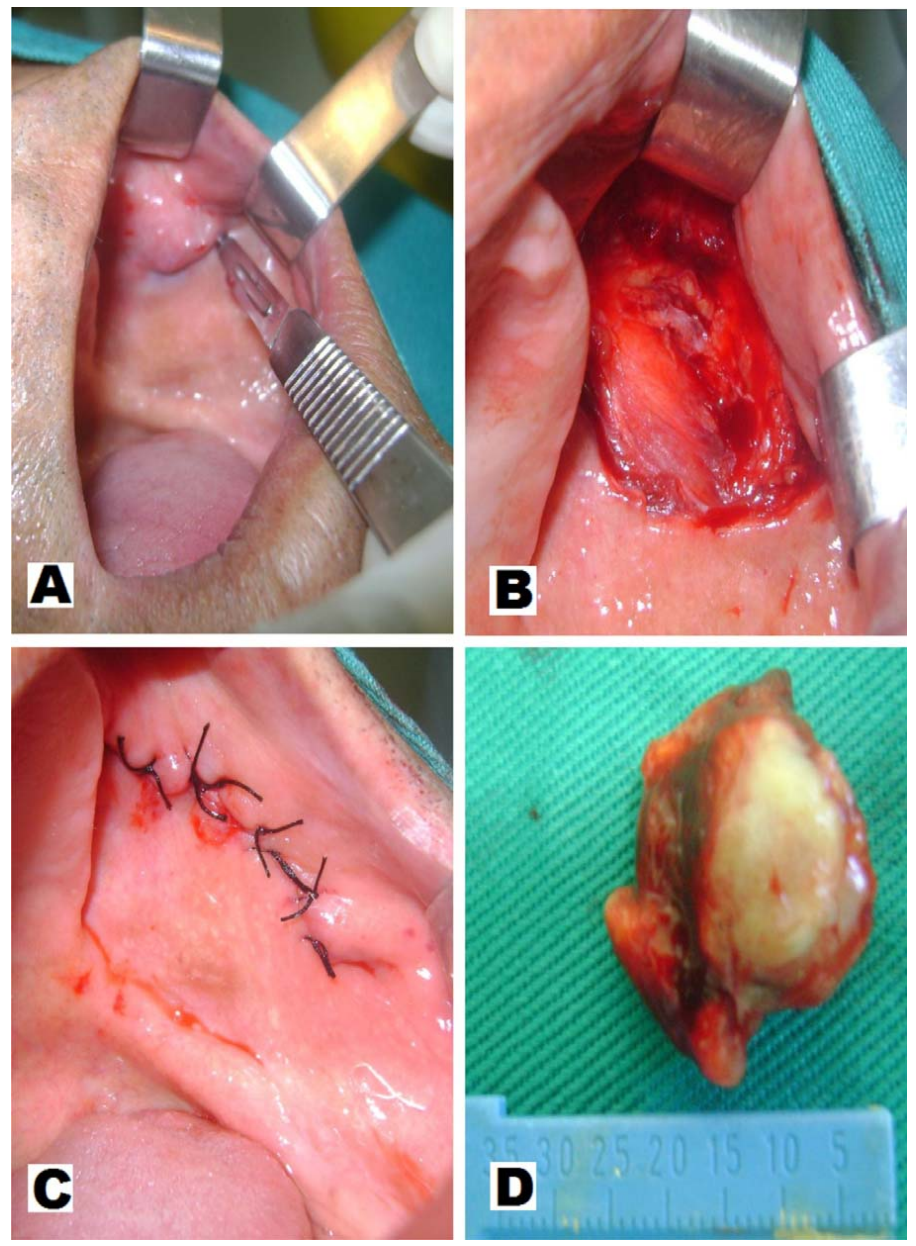

Fig. (3). Excisional biopsy: A - wedge incision. B - removal of debris. C - suture. D - surgical specimen.

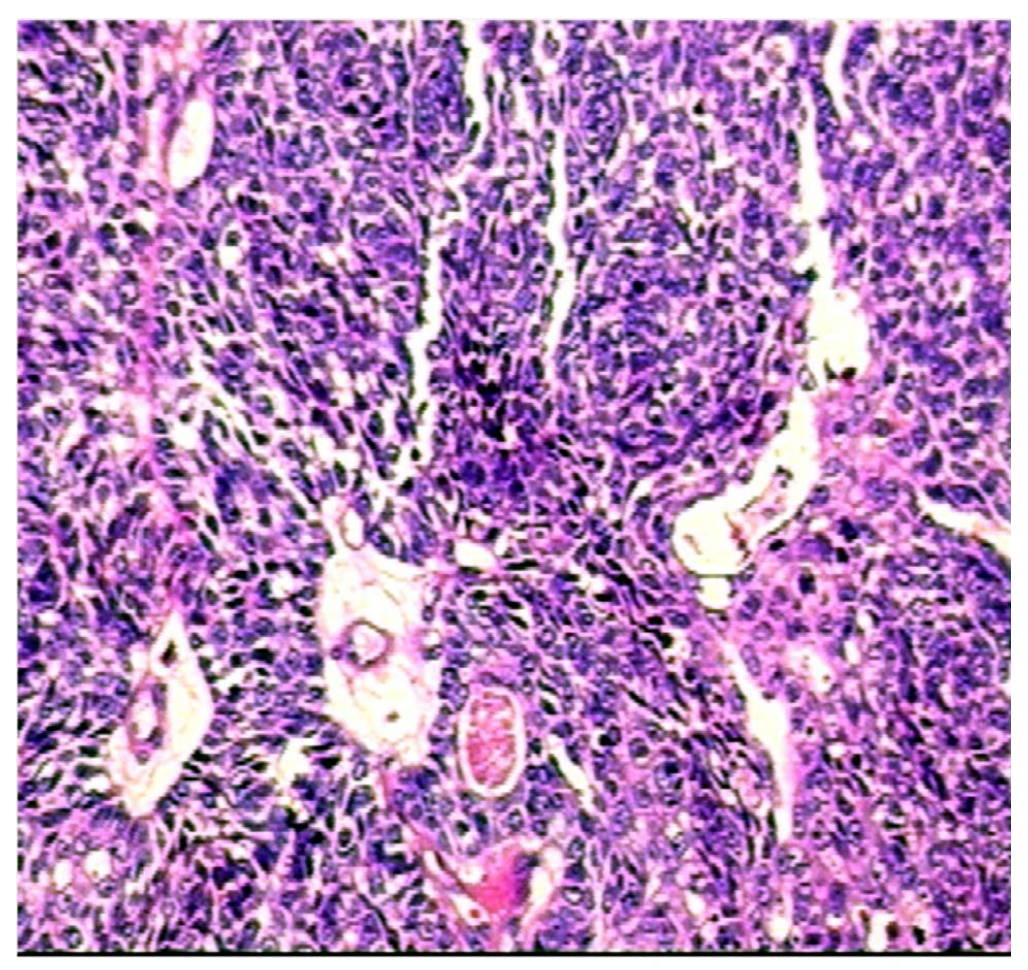

Fig. (4). HE, 200x: ductal formations showing inner layer of cuboidal cells and also proliferation of solidly arranged polygonal cells. 


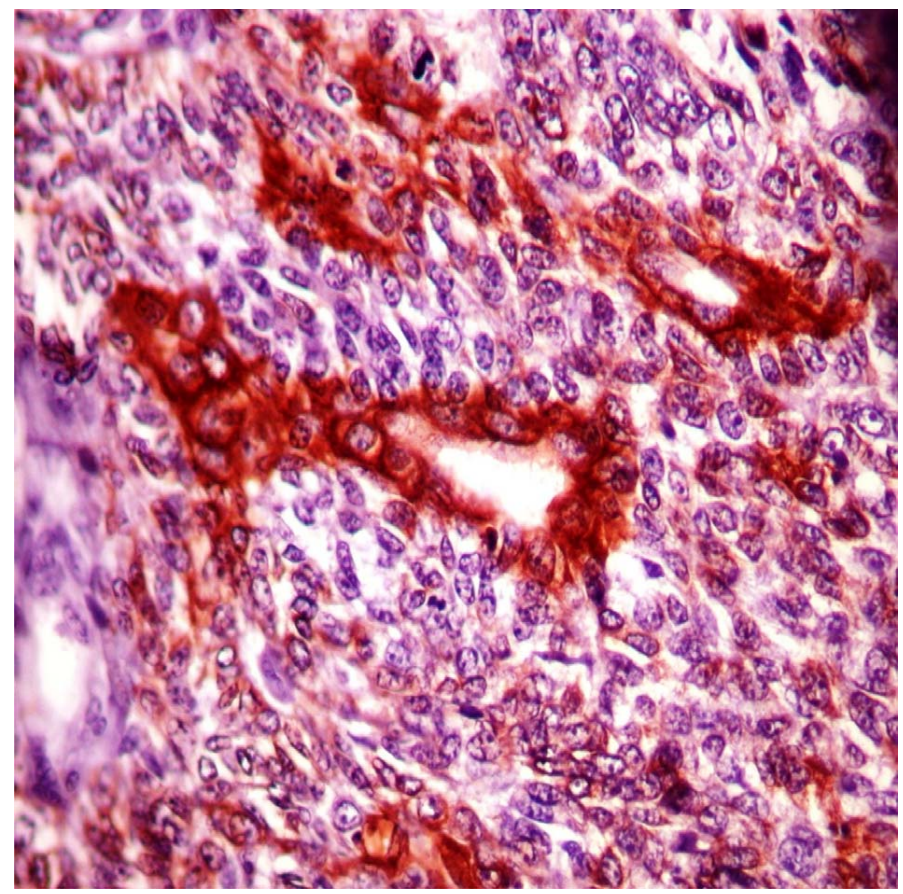

Fig. (5). Immunohistochemistry, 200x - Protein positivity for AE1/AE3 proteins in the inner cuboidal cells of the ductal formations.

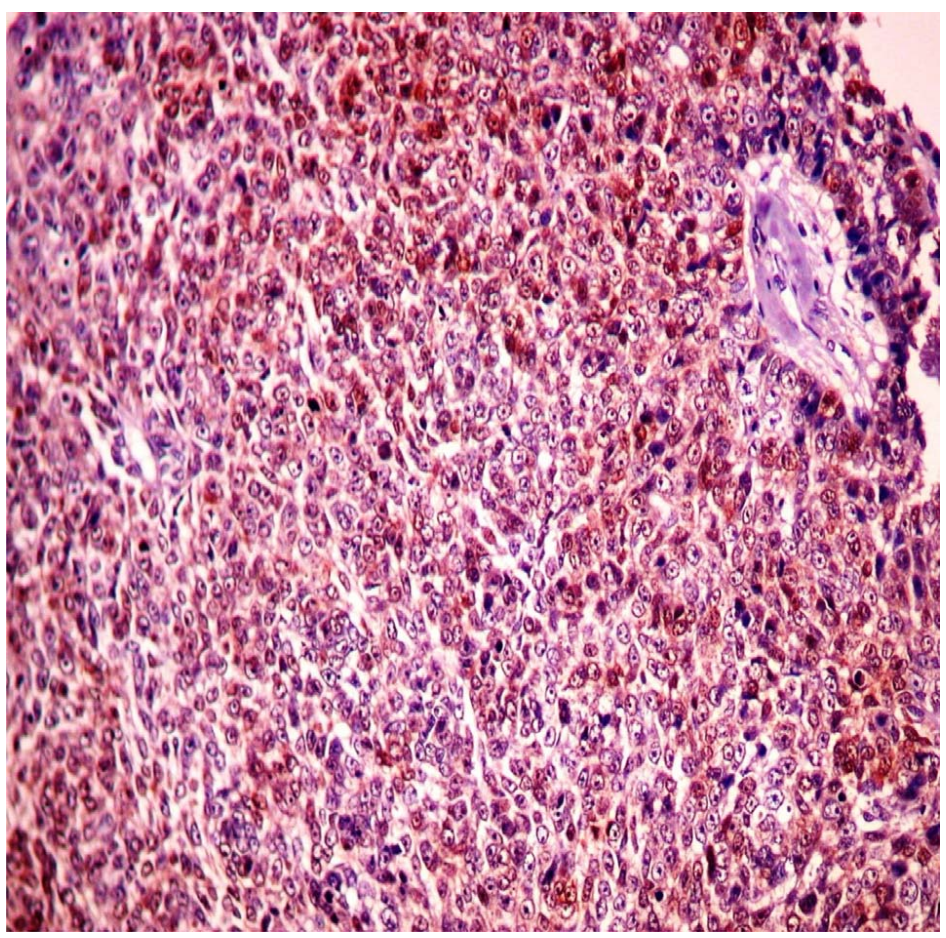

Fig. (6). Immunohistochemistry, 200x - Diffuse staining for S100 protein in tumor cells.

\section{DISCUSSION}

Epithelial-myoepithelial carcinoma (EMC) was first described in 1972 by Danath et al. There are only a few cases reported in the literature until now $[5,6]$. Historically, the lesion has been reported with different terminologies, and sometimes regarded as a benign neoplasia, until WHO, in 1991, defined it as a malignant neoplasm of the salivary gland $[1,3,4]$.
Most authors have reported that the lesion is more prevalent in adults, with higher incidence in the seventh decade of life $[3,5,7]$. The females are affected in $60 \%$ of the cases [ 1 , $3,5,7,8]$. Disagreeing regarding this tendency of female gender involvement, this and some other reports affected male patients [7].

EMC most commonly affects parotid and submandibular glands, followed by minor salivary glands. It has various 


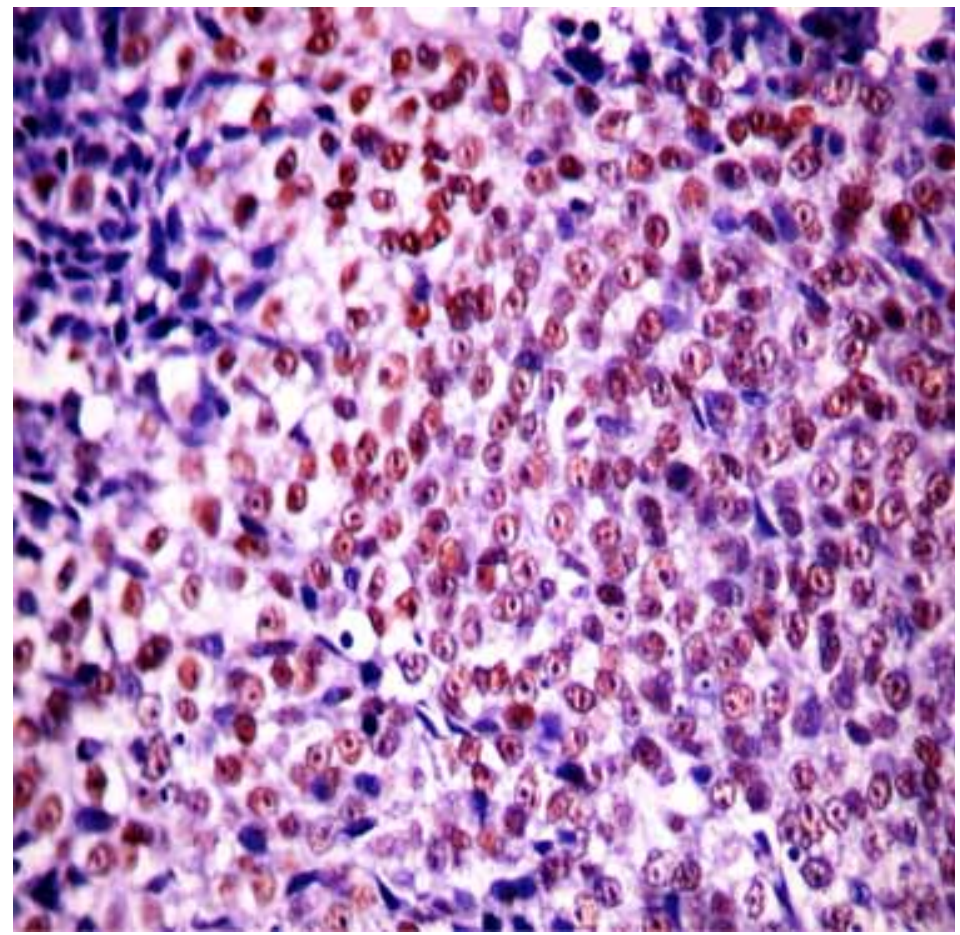

Fig. (7). Immunohistochemistry, 200x - Nuclear staining for $\mathrm{p}-63$ protein.

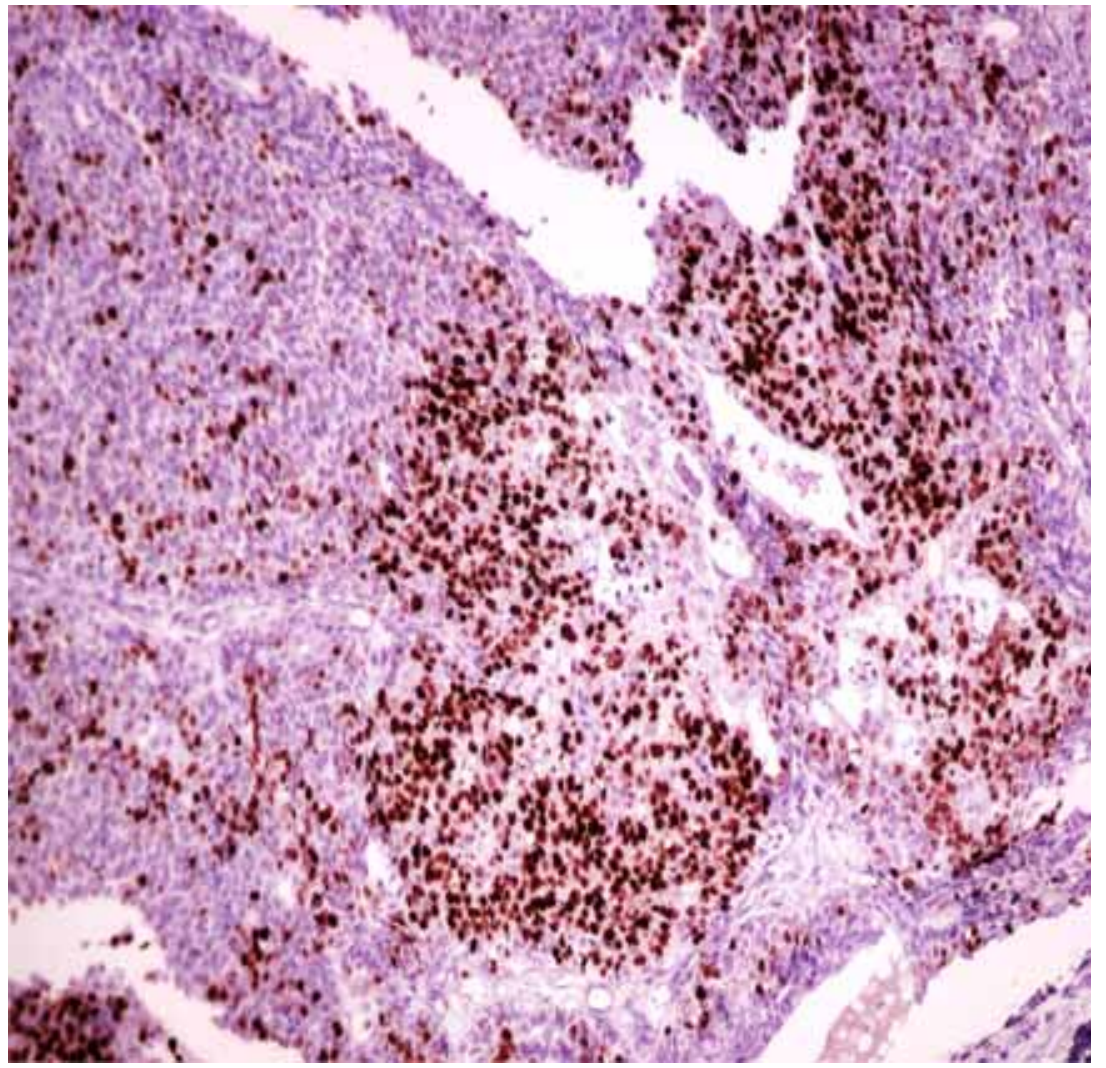

Fig. (8). Immunohistochemistry, 200x - Intense nuclear staining for Ki67 protein in several tumor cells.

sites of presentation as the basis and the womb of the tongue, nasal cavity, lacrimal glands [1-4, 9]. EMC also has a report involving another type of gland, as well as a report in bronchia [10]. Stands out as rare a presentation of EMC in the oral mucosa, especially because this is a variant of highgrade transformation.
Classically, EMC presents behavior of low malignancy $[1,3,4]$. In this clinical report, it was verified an exception, when it was identified a high degree of transformation tumor. It agrees with another study [7], which described the histological and immunohistochemical picture of three other cases of EMC classified as high-grade transformation. Ac- 
cording to Roy et al. [7], the criteria for defining high degree of transformation in EMC must include margins of the lesion showing infiltration, cellular atypia, disorganization of the external myoepithelial layer and the need for complementary examination to prove its histogenetic origin. Such characteristics were identified in the case described herein.

In this report, was highlighted by the patient that the current lesion corresponded to a local recurrence, which agrees with Matos et al. [1], who reported a case of local recurrence after four years of the removal of the lesion and also agrees with Esposito et al. [4], who refereed a variation on the locoregional recurrence in percentage terms, ranging from $28 \%$ to $50 \%$. Additionally, these authors emphasized that the EMC has a low mortality rate, but also has a strong local and regional aggressiveness, whether it presenting high or low degree of transformation.

Histopathologically, the EMC has rounded epithelial cells, clear polygonal cells and a myoepithelial component in a solid arrangement that may resemble other salivary gland tumors. The differential diagnosis involves mainly myoepithelial carcinoma (MC), pleomorphic adenoma (PA) and adenoid cystic carcinoma (ACC) [2, 3, 5-7].

To properly differentiate EMC from other similar salivary gland neoplasms, is necessary a careful histopathological examination, which seeks to identify the presence of two cell populations: epithelial and myoepithelial cells. The identification of a solid ductal arrangement with an inner layer of epithelial cells and an outer layer of myoepithelial cells, can be done on EMC. However the PA, ACC and MC may have similar structural components depending on the degree of cellular differentiation. On these occasions, special techniques such as immunohistochemistry should be performed $[2,5,7]$.

The EMC diagnosis is usually based on microscopy, however, in cases similar to that described (with a high degree of transformation), the use of immunohistochemistry in the diagnosis consists in one of the prevailing alternatives for closing this framework $[7,8]$.

Regarding the choice of antibodies used in immunohistochemical assessment of this case, the anti-p63 is a selective marker for nuclear staining, with a significant markup for myoepithelial cells [3, 7]. This report corroborates the information from van Tongeren et al. [3], that the marked expression of p63 protein reveals its participation in the morphogenesis of the EMC.

The S-100 protein can be used for differential diagnosis between EMC and ACC, which also possesses two cell layers. However, the positive staining for S-100 protein in ACC only occurs in the inner layer duct, and while in EMC it only is positive in the external ductal layer as can be seen in this case report $[2,3]$.

The Ki-67 protein is related to cell proliferation. It is found throughout the entire cell cycle, and it can bring additional data regarding the biological behavior of the lesion. According Seethala, Barnes and Hunt [6], myoepithelial cells of the EMC demonstrate high proliferative and mitotic activity, indicating the significant $\mathrm{Ki}-67$ positivity in the myoepithelial component. In the case presented here, it is emphasized that this protein has facilitated the understanding that it is a variant of high degree EMC.

In a similar case to the reported here, Matos et al. [8], confirmed the diagnosis of EMC using the technique of immunohistochemistry. They did it using cytokeratin 7 and 8 , which showed positivity in the internal ductal structures and also using smooth muscle actin (SMA), which was positive in the external cells. In this case we used the antibodies to cytokeratin AE1/AE3, confirming a cell group of epithelial origin and finally observing, along with other immunohistochemical findings, a profile consistent with epithelialmyoepithelial carcinoma with high grade transformation [7].

According to the literature, the treatment is varied and the main method is surgery with a safety margin and if necessary, subsequent using of radiotherapy and chemotherapy. In some cases, treatment may include enlargement of the incision and neck dissection with lymph node emptying [2, $4,7-9]$. In the present clinical case the initial treatment was a local surgical incision with safety margin, even without prior confirmation of a malignant lesion of salivary gland. Since it was confirmed the malignant nature of the lesion, the patient was referred to an oncology service.

In conclusion, it is noteworthy, therefore, the importance of critical and reflective evaluation by the dentist as well as diagnostic and prognostic value of histopathology and immunohistochemistry, especially for cases of malignant tumors that do not exhibit clinical features that may characterize such condition.

\section{CONFLICT OF INTEREST}

We wish to declare that the submitted work is original and has not been submitted or published elsewhere. Moreover, all authors have read and approved the manuscript and agree with the current submission. Finally, there are no potential conflicts of interest.

\section{ACKNOWLEDGEMENTS}

We are very thankful to Centro de Anatomopatologia S/C Ltda (UNILAP), Campina Grande - Paraiba / Brazil.

\section{REFERENCES}

[1] Kumai Y, Ogata N, Yumoto E. Epithelial-myoepithelial carcinoma in the base of the tongue: a case report. Am J Otolaryngol 2006; 27 : 58-60.

[2] Alves PM, Silva LAC, Godoy GP, Gomes DQC, Queiroz LMMG, Galvão HC. Unusual epithelial-myoepithelial carcinoma in palatecase report and immunohistochemical study. J Clin Exp Dent 2010; 2: $22-5$.

[3] Van Tongeren J, Creytens DHKV, Meulemans EV, Bondt RBJ, Jong J, Manni JJ. Synchronous bilateral epithelial-myoepithelial carcinoma of the parotid gland: case report and review of the literature. Eur Arch Otorhinolaryngol 2009; 266: 1495-500.

[4] Esposito E, Cassiano B, Cinquegrani F. Salivary glands: report of a rare case of myoepithelial carcinoma involving tongue base treated by $\mathrm{CO}_{2}$ laser. Acta Otorhinolaryngol Ital 2009; 29:156-9.

[5] Kusafuka K, Takizawa Y, Ueno T, et al. Dedifferentiated epithelialmyoepithelial carcinoma of the parotid gland: a rare case report of immunohistochemical analysis and review of the literature. Oral Surg Oral Med Oral Pathol Oral Radiol Endod 2008; 106: 85-91.

[6] Seethala RR, Barnes EL, Hunt JL. Epithelial-myoepithelial carcinoma: a review of the clinicopathologic spectrum and immunophenotypic characteristics in 61 tumors of the salivary glands and upper aerodigestive tract. Am J Surg Pathol 2007; 31: 44-57. 
[7] Roy P, Bullock MJ, Perez-Ordonez B, Dardick I, Weinreb I. Epithelial myoepithelial carcinoma with high grade transformation. Am J Surg Pathol 2010; 34: 1258-65.

[8] Matos FR, Miranda JL, Mequita ATM, Santos CRR, Freitas RA. Epithelial-myoepithelial carcinoma in the ventral surface of the tongue. Braz J Otorhinolaryngol 2010; 76:540.
[9] Ramraje SN, Bharambe BM, Zode R. Epithelial myoepithelial carcinoma of the submandibular salivary gland. Bombay Hosp J 2010; 52: 53-8.

[10] Chao TY, Lin AS, Lie CH, Chung YH, Lin JW, Lin MC. Bronchial epithelial-myoepithelial carcinoma. Ann Thorac Surg 2007; 83: 689-91.

Received: May 02, 2012

Revised: June 06, 2012

Accepted: June 07, 2012

(c) Lima et al.; Licensee Bentham Open.

This is an open access article licensed under the terms of the Creative Commons Attribution Non-Commercial License (http://creativecommons.org/licenses/by-nc/3.0/) which permits unrestricted, non-commercial use, distribution and reproduction in any medium, provided the work is properly cited. 